\title{
SLEEP DISORDER
}

\section{A possible cause of attention deficit in children and adolescents with Chiari malformation type II}

\author{
Paulo Sérgio Azeredo Henriques Filho', Riccardo Pratesi ${ }^{2}$
}

\begin{abstract}
Background: Attention deficit may be related to sleep disorders in Chiari malformation type II (CMII). Our aim is identify sleep disorders and their specific contribution in attention deficit. Method: We selected 24 patients with CM II and 24 without CM II. DSM-IV criteria and a neuropsychological analysis were applied in all. All patients underwent full night polysomnography. Results: 14 CM II patients presented sleep apnea syndrome, REM sleep behavior disorder and periodic limb movement in sleep; six patients without CM II presented sleep apnea syndrome. Among these patients, 12 (six with CM II and six without CM II) presented attention deficit related to the sleep disorders. Conclusion: Sleep disorders may impair cognitive functions, as attention, and contribute to poor quality of learning also in patients with CM II.
\end{abstract}

KEY WORDS: polysomnography, REM sleep behavior disorder, apnea, cognition, attention deficit disorder.

\section{Distúrbios do sono: possivel causa de déficit de atenção em crianças e adolescentes com malformação de Chiari tipo II}

Resumo - Introdução: Déficits de atenção podem estar relacionados a distúrbios do sono em indivíduos com malformação de Chiari tipo II (CM II). Nosso objetivo é identificar distúrbios do sono e sua contribuição para a ocorrência de déficit de atenção. Método: Foram selecionados 24 pacientes com CM II e 24 sem CM II. Todos foram submetidos à avaliação neuropsicológica, aos critérios do DSM-IV e a polissonografia. Resultados: 14 pacientes com CM II apresentaram sindrome da apnéia do sono, distúrbio do comportamento da fase do sono REM e movimentos periódicos dos membros em sono; seis pacientes sem CM II apresentaram síndrome da apnéia do sono. Entre estes pacientes, 12 (seis com CM II e seis sem CM II) apresentaram déficit de atenção relacionado a distúrbios do sono. Conclusão: Distúrbios do sono podem prejudicar funções cognitivas, como a atenção, contribuindo para a piora da qualidade de aprendizado também em pacientes com CM II.

PALAVRAS-CHAVE: polissonografia, distúrbio do comportamento da fase do sono com movimentos oculares rápidos, apnéia, cognição, transtorno do déficit de atenção.

The central nervous system (CNS) abnormality characterized by herniation of cerebellar tonsils below the plane of foramen magnum was initially described by Chiari in 1891. Subsequently, the same author expanded the spectrum of abnormalities of the craniocervical junction including disorders that are currently recognized as Chiari malformation (CM) type I, II, III and IV. These congenital disorders disclose complex physical and neuropsychological symptomatology and are associated with developmental anomalies of both the spine and brain'. The CM type II (CM II) is characterized by the descent of the inferior vermis and cerebellar hemispheres through the foramen magnum with a displacement of the brain stem (medul- la, fourth ventricle, and lower portion of the pons) inside the spinal canal, resulting in aqueduct and fourth ventricle elongation ${ }^{1,2}$. Myelomeningocele is present in almost all children with CM II and hydrocephalus is concomitantly seen in more than $70 \%$ of cases'. The increased prevalence of a variable degree of encephalic developmental anomalies observed in children with CM II may negatively affect their cognition ${ }^{3}$. Although presently, mostly due to improved diagnostic methods and precocious treatment, children with myelomeningocele and hydrocephalus are more likely to have an IQ within normal range ${ }^{4}$. Consequently, in spite of the variable degree of CNS abnormalities, the majority of children with CM II are apt to

${ }^{1}$ Graduation Program in Medical Sciences, Brasilia University School of Medicine, Brasília DF, Brazil; ${ }^{2}$ Senior Fellow Researcher.

Received 11 August 2008, received in final form 6 October 2008. Accepted 18 November 2008.

Dr. Paulo Sérgio Azeredo Henriques Filho - MILN TR 06, CH 232, C2, Lago Norte - 71540-065 Brasilia DF - Brasil. E-mail: pazeredo@linkexpress.com.br 
attend and follow a normal school program showing satisfactory performance and a socially acceptable degree of continence and behavior ${ }^{4}$. Besides the potential presence of cognitive difficulties, CM II patients are, mostly due to their brain stem anomalies, often affected by sleep disorders, the more frequently observed being sleep apneas, central hypoventilation and pulmonary restrictive disease ${ }^{3,5}$. Periodic limb movement in sleep (PLMS) may appear in association to spinal anomalies ${ }^{6}$, and would be another sleep disorder which could result in further cognitive impairment ${ }^{7}$. PLMS in CM II patients were never previously described, although Kaplan and $\mathrm{Oksuz}^{8}$ reported this disorder in a CM I patient. Another sleep disorder that could eventually contribute to a poor school performance would be the REM sleep behavior disorder (RBD). Also this disorder has been never observed previously in CM II patients, although Lapierre and Montplaisir ${ }^{9}$ reported a single case of RBD in a CM I patient.

In general, sleep disorders have been referred as a cause of behavioral and school performance difficulties leading to a possible diagnosis of attention deficit with or without associated hyperactivity ${ }^{10}$ and, in the specific case of children with CM II, they may aggravate the preexisting cognitive impairment consequent to a variable degree of CNS dysfunction. Unfortunately, sleep disorders are rarely considered as potential source of inattentive behavior in children with CM II, since all their handicaps are generally considered to be secondary to their malformations and sleep disorders, as cause of inattention and hyperactivity, seldom receive a careful though. Davidovitch et al." described high prevalence of attention deficit in CM II patients. Dise and Lohr ${ }^{12}$ described deficits in conceptual reasoning abilities, considering the coexisting brain malformations as the responsible for the disorder, but, to the present time, no studies have been made focusing the possible association between of sleep disorders and attention deficit in CM II patients.

The purpose of the present study was to assess the frequency of sleep disorders in a group of school children and adolescents affected by CM II, comparing their attention capacity with a group of controls paired by age, attempting to ascertain a possible correlation between sleep disorders and attention deficits in patients affected by CM II.

\section{METHOD}

\section{Study group}

This case-control study was carried out between March 2005 and February 2007, after the approval of the Institutional Ethic Committee of the Sarah Rehabilitation Hospital of Brasilia, as well as the approval of relatives and/or patients involved in the study. The study group was selected among patients seen at the hospital outpatient clinic due to varied complaints and di- agnosed as having CM II and was selected after a complete medical history and physical examination, including the assessment of the body mass index (BMI) and neck circunference (NC) 24 children and adolescent were selected according to the following criteria: (a) being born with spina bifida, and having undergone corrective spinal surgery in neonatal period; (b) having an age comprised between seven and 16 years; (c) attending a normal school and a corresponding grade for their age; (d) disclosing a T1-weighted magnetic resonance imaging (MRI) conclusive for presence of CM II; (e) being considered of normal intelligence on neuropsychological evaluation. Children reported as being affected by respiratory, cardiovascular and neurological disorders or other ailments aside CM II, or being in use of medication that could interfere with their behavior, or with their sleep pattern, were excluded from the study. The control group was composed by 24 children without CM II, paired by age, of the same socioeconomic level and pertaining to the same school.

\section{Sleep study}

Full night polysomnography evaluation was carried out utilizing a polygraphic digital system (Sleepscan Bio-Logical System Corporation, San Diego, CA, USA). Each subject underwent one or two full night polysomnography (depending on his or her adaptation to the sleep laboratory settings). Digital recordings included electroencephalogram (EEG) adopting identical montage ( $\mathrm{C} 3-\mathrm{A} 2, \mathrm{C} 4-\mathrm{A} 1, \mathrm{O} 1-\mathrm{A} 2$ and $\mathrm{O} 2-\mathrm{A} 1$, according to the International 10-20 system), electro-oculogram, chin electromyogram (EMG) electrocardiogram, upper airway sound, respiratory effort using piezoelectric belts over the chest and abdomen, and airflow through the nose and mouth (monitored through a cannula-pressure transducer and oronasal thermocouples). We also recorded bilateral surface EMG from arms (biceps muscles) and legs (anterior tibial muscles). Oxyhaemoglobin saturation was monitored by pulse oximetry and subjectsí behavior during sleep was monitored by continuous video and sound recordings. All patients disclosing any type of movement disorders during sleep or with history of possible RBD underwent EEG recordings with a complete 21 electrode montage.

\section{Scoring}

Sleep stages, patientsí movements and abnormal respiratory events were scored by two accredited polysomnography technologists according to the standard criteria of Rechtschaffen and Kales ${ }^{13}$. The REM sleep phase was scored separately in accordance with the method described by Lapierre and Montplaisir ${ }^{9}$, modified according to Consens et al. ${ }^{14}:$ mini-epoch and epoch duration were respectively established as three and 30 seconds. The onset of a REM sleep period was determined by the presence of desynchronized EEG, bursts of rapid eye movements, and suppression of EMG activity. The REM sleep phase termination was identified by the presence of an interval of relatively low-voltage mixed frequency on the EEG recording between two sleep spindles or K-complexes, without REM or movements 
arousals during this interval and if the interval is less than three minutes long. During the REM sleep phase, each 30-second epoch was scored and analyzed to establish the proportion of epochs showing a predominance of abnormally elevated chin muscle background tone (tonic component), and was also scored and analyzed the proportion of three-second mini-epochs (within the 30-second REM sleep epochs) showing bursts of EMG activity (phasic component). Epochs were scored as tonic or atonic depending on whether tonic chin EMG activity $(2 \mu \mathrm{V}$ above EMG background) was present for more or less than $50 \%$ of the epoch. We utilized thirty percent of REM sleep epochs with abnormalities to establish as the cut-off value.

In children, the hypopnea and apnea duration cut-off utilized was two or more respiratory cycles ${ }^{15}$. These events were only considered significant when associated to an oxyhaemoglobin desaturation equal to or greater than $4 \%$ independently from the onset of subsequent arousal, partial arousal or awakening ${ }^{15}$. The total duration of arterial desaturation was quantified as the accumulated span of arterial oxyhaemoglobin saturation below $90 \%$. The apnea-hypopnea index (AHI) was defined as the sum of apneic and hypopneic episodes per hour. AHI were evaluated according to the patientís age. In children and adolescents, between one and five episodes per hour were considered mildly abnormal, between six and 10 as moderate, and above 10 as severely abnormal. Periodic limb movements were scored according Zucconi et al. ${ }^{16}$ classification. The presence of attention deficit was determined in agreement with the DSM-IV criteria and by the application of the composite teacher rating scale (ComTRS) ${ }^{17}$ which assesses five factors: hyperactivity, independent functioning, inattention, socialization and anxiety.

\section{Statistical analysis}

Variables showing normal distribution were expressed as mean value \pm standard deviation and an abnormal distribution as median values. Differences among mean of continuous variables were calculated by Student $t$ test . A significance level of $\mathrm{p}<0.05$ was used $^{18}$.

\section{RESULTS}

The CM II group was composed by 15 boys (age range: seven to 14 years) and nine girls (age range: seven to 14 years) mean age of the group being: $10.19 \pm 0.54$ years. The control group comprised 13 boys (age range: seven to 11 years) and 11 girls (age range: seven to 13 years) mean age $9.82 \pm 2.09$ years. No significant difference was found neither BMI values (19.13 \pm 6.62 in controls patients and 16.19 \pm 1.56 in CM II patients), nor in neck circunference (30.42 \pm 3.45 in controls patients and 27.35 \pm 3.10 in CM II patients).

Mean values and standard deviations of sleep phases, wake after sleep onset, sleep efficiency, total sleep time in hours and arousal index can be seen in Table 1.

Fourteen of the 24 (58\%) CM II patients disclosed episodes of central sleep apnea, while in controls six out of $24(25 \%)$ showed episodes of obstructive sleep apnea. The central AHI in CM II was 5.10 44.53 , and in controls was $0.40 \pm 0.28(p<0.05)$. The obstructive $A H I$ in $C M I I$ was $0.21 \pm 0.08$, and in controls was $3.72 \pm 3.63(\mathrm{p}<0.05)$. In CM II patients, the increase $\mathrm{AHI}$ was mainly consequent to the presence of central apnea and hypopnea, while in controls it was due to obstructive apneas and hypopnea. The AHI values among CM II patients and controls that did not fulfill criteria to characterize a sleep apnea syndrome were respectively $0.62 \pm 0.13$ and $0.29 \pm 0.22(p<0.05)$. PLMS were observed among 11 of the 24 (45.8\%) CM II patients. No abnormal PLMS index was observed in the control group. PLM index was $8.02 \pm 18.24$ in CM II, and $0.36 \pm 0.68$ in controls $(\mathrm{p}<0.05)$. RBD was present in six of the $24(25 \%) \mathrm{CM}$ II patients and in none of the controls.

Table 1. Mean values (in percentage) and standard deviations of sleep stages, total sleep time, wake after sleep onset (WASO), sleep efficiency, total sleep time in hours and arousal index in CM II patients and controls.

\begin{tabular}{lccc}
\hline & CM II & Controls & T test (p value) \\
\hline No-REM sleep stage 1 (\%) & $1.50 \pm 1.63$ & $1.10 \pm 2.37$ & NS \\
No-REM sleep stage 2 (\%) & $38.00 \pm 7.42$ & $42.44 \pm 15.16$ & NS \\
No-REM sleep stage 3 (\%) & $3.50 \pm 1.45$ & $5.10 \pm 4.34$ & NS \\
No-REM sleep stage 4(\%) & $32.10 \pm 6.77$ & $25.42 \pm 7.25$ & NS \\
REM sleep phase (\%) & $24.95 \pm 7.00$ & $20.58 \pm 7.43$ & NS \\
WASO & $15.20 \pm 9.90$ & $8.21 \pm 2.50$ & 0.03 \\
Sleep efficiency & $87.65 \pm 6.83$ & $93.00 \pm 8.77$ & NS \\
Total sleep time (in hours) & $7.06 \pm 1.27$ & $8.30 \pm 0.87$ & NS \\
Arousal index & $7.85 \pm 4.03$ & $3.39 \pm 2.28$ & 0.05 \\
\hline
\end{tabular}

REM, rapid eye movements; WASO, wake after sleep onset; significance leve l of $p<0.05$; NS, not significant. 
Table 2. Types of apneas and hypopneas, mean value and standard deviation of the apneas/hypopneas duration in CM II patients and controls

\begin{tabular}{|c|c|c|c|}
\hline & CM II & Controls & T test ( $p$ value) \\
\hline \multicolumn{4}{|l|}{ Central apnea } \\
\hline More than two standard deviation from the median & $20.02 \pm 22.00$ & $14.73 \pm 3.51$ & NS \\
\hline More or equal to two respiratory cycles & $11.37 \pm 5.54$ & $13.13 \pm 3.43$ & NS \\
\hline \multicolumn{4}{|l|}{ Obstructive apnea } \\
\hline More than two standard deviation from the median & $44.56 \pm 55.56$ & $12.91 \pm 2.80$ & 0.00 \\
\hline More or equal to two respiratory cycles & $16.70 \pm 10.75$ & $11.72 \pm 2.86$ & NS \\
\hline \multicolumn{4}{|l|}{ Mixed apnea } \\
\hline More than two standard deviation from the median & $9.50 \pm 0.84$ & $11.20 \pm 0.0$ & NS \\
\hline More or equal to two respiratory cycles & $7.80 \pm 1.27$ & $7.70 \pm 0.0$ & NS \\
\hline \multicolumn{4}{|l|}{ Hypopnea } \\
\hline More than two standard deviation from the median & $49.34 \pm 46.93$ & $15.40 \pm 1.70$ & 0.00 \\
\hline More or equal to two respiratory cycles & $19.13 \pm 8.33$ & $14.72 \pm 2.43$ & NS \\
\hline
\end{tabular}

Significance level of $p<0.05$; NS, not significant.

Table 3. Mean values and standard deviation of the longest oxy-haemoglobin desaturation events, duration of the events, index of isolated events and index related to apnea/hypopnea events in CM II patients and controls.

\begin{tabular}{lccc}
\hline & CM II & Controls & T test ( $p$ value) \\
\hline Desaturation events above two standard deviation from the median & $31.45 \pm 49.85$ & $22.60 \pm 4.25$ & 0.00 \\
Mean time span of desaturation events & $25.12 \pm 24.32$ & $16.82 \pm 27.41$ & $\mathrm{NS}$ \\
Desaturation index during total sleep time & $5.88 \pm 10.71$ & $3.72 \pm 3.63$ & $\mathrm{NS}$ \\
Desaturation index related to apnea/hypopnea & $5.10 \pm 4.53$ & $3.72 \pm 3.63$ & $\mathrm{NS}$ \\
\hline
\end{tabular}

Desaturation index, number of desaturation per hour; Longest oxy-haemoglobin desaturation events, events above two standard deviation from the median; Significance level of $\mathrm{p}<0.05$; NS, not significant.

Table 4. Analysis of attention deficit in CM II patients and controls with and without sleep disorders (RBD, central sleep apnea, PLMS in CM II patients, obstructive apneas in controls patients).

\begin{tabular}{|c|c|c|c|c|c|c|}
\hline & \multicolumn{2}{|c|}{ CM II } & \multirow{2}{*}{$\frac{T \text { test }}{p \text { value }}$} & \multicolumn{2}{|c|}{ Controls } & \multirow{2}{*}{$\frac{T \text { test }}{p \text { value }}$} \\
\hline & With SD & Without SD & & With SD & Without SD & \\
\hline With AD & 6 & - & 0.01 & 6 & - & 0.01 \\
\hline Without AD & 8 & 10 & NS & - & 18 & 0.00 \\
\hline Total & 14 & 10 & & 6 & 18 & \\
\hline
\end{tabular}

AD, attention deficit; SD, sleep disorders; Significance level of $p<0.05$; NS, not significant.

An assessment and comparison between the CM II patients and controls of the mean of apnea and hypopnea duration, the longest apneic and hypopneic event and the apneic event type were also performed and the results can be seen in Table 2.

Oxy-haemoglobin saturation abnormalities can be seen in Table 3.

The relationship between the presence of sleep disorders (RBD, central sleep apnea, PLMS in the CM II patients and obstructive apneas in controls patients) and the co- existence of attention deficit assessed by DSMI-V and EA$\mathrm{Cl}-\mathrm{P}$ scales can be appreciate in Table 4.

\section{DISCUSSION}

No relationship could be found between increased body mass index and neck circumference, and the presence of obstructive sleep apneas (OSA) both in CM II patients and in controls. This can be explained by the fact that none of the individuals included in the study was overweight or obese. Another probable explanation could 
be that among CM II patients sleep apneas are generally caused by brain stem malformations being consequently of central origin ${ }^{5,19}$. Among controls the main cause for sleep apneas was the presence of allergic rhinitis.

In CM II patients, even in those suffering from isolated RBD, was observed an increase of NREM stage 4 and of REM sleep phases (Table 1), which was probably consequent to sleep deprivation. In the presence of sleep fragmentation, the sleep generators try to preserve slow wave sleep, increasing the delta band frequency and the percentage of NREM slow wave sleep ${ }^{20}$. The concomitant increase in wake after sleep onset (WASO) and arousal index and the consequent decrease in sleep efficiency and total sleep time, mirror the deleterious effects that sleep disorders, mainly SAS, RBD and PLMS, may cause on the sleep architecture and result in the appearance of attention disorders in these patients ${ }^{10}$.

Sleep disorders were detected in 14 CM II patients and in six controls (Table 4). The most prevalent disorders among CM II patients were central apneas (12/14), RBD (5/14) and PLMS (3/14). In contrast, controls showed an increased frequency of obstructive apneas, predominantly caused by airway pathologies, allergic rhinitis being the most common $(6 / 24)$. The increased frequency of sleep disorder in CM II patients, may be explained by the variable degree of brain stem abnormalities in CM II patients ${ }^{21,22}$, generally involving midbrain, pons and medulla oblongata, where are localized neurons of the respiratory regulation, and neurons of the REM sleep and of the movement control during sleep ${ }^{23-25}$. Analyzing these data, it is possible to conclude that sleep disorders are more prone to cause attention deficit than the presence of $\mathrm{CM}$ II alone, since in CM II patients without sleep disorders no attention deficit could be detected (Table 4).

Sleep apneas may cause and increased fragmentation of sleep both in CM II and in controls, mainly due to the coexisting hypoxemia or to intermittent oxy-haemoglobin desaturarion (Table 3), which would be most deleterious to sleep architecture, than another sleep disorder without hypoxemia ${ }^{26}$.

CM II patients disclosed longest apnea and or hypopnea events when compared to controls patients (Table 2). This difference is probably due to a functional and or anatomical disconnection between the aortic and carotid chemoreceptors and the glossopharyngeal nerve ${ }^{27}$. Another possibility would be the presence of functional deficits of the retrotrapezoideus nucleus (RTN), which is localized in the medulla oblongata, and is frequently involved in CM II brain stem abnormalities. The RTN nucleus is responsible to the respiratory control from changes in $\mathrm{pH}$, in the presence of hypoxemia, and from $\mathrm{CO}_{2}$ elevation ${ }^{28}$.
The increased time of oxy-haemoglobin desaturation, among CM II patients (Table 3), consequent to episodes of apnea and or hypopnea, can probably be explained, as in the case of apneic events, by functional abnormalities in the chemoreceptor activity of the peripheral (aortic, carotid) and or in the central nucleus. In CM II, these chemoreceptors are probably affected by the malformations $s^{27,29,30}$.

The behavioral evaluation of CM II children, applying the ComTRS and the DSM-IV criteria, disclosed 12 cases of attention deficit (Table 4). Hyperactivity was concomitantly diagnosed in three children. These abnormalities were more frequently seen among CM II patients with sleep apneas (SAS) than in those without this sleep disorder or in patients with RBD alone. The difference between CM II patients with SAS and patients with RBD alone was probably due to the greater impairment of sleep architecture in CM II patients with SAS, which could be consequence of the deleterious effect of chronic or intermittent hypoxia on cognition in these children ${ }^{26}$.

The relative lesser repercussion on sleep architecture and the scarce clinical expression observed in CM II patients with RBD when compared to patients with RBD, but without CM II, is probably due to the frequent impairment of movements present in CM II patients ${ }^{4}$ that preclude intensive and energetic dream out movements.

With the exception of one patient, that disclosed a severe PLMS index, PLMS were found in association with abnormal respiratory events in all the remaining CM II patients. This difference probably was related to degree of spinal cord malformation with hydrosiringomyelia, which involved propiospinal neurons, presented in 40 a $88 \%$ of the CM II patients ${ }^{30}$. In accordance with Nogués et al. ${ }^{6}$, in CM II patients there is a relationship between the presence of PLMS and spinal cord abnormalities. Abnormalities of the spinal cord may result in hyperexcitability of spinal regions affected by malformations, leading to the appearance of $\mathrm{PLMS}^{6}$. The CM II patient with severe PLMS index was also affected by attention deficit, reinforcing the hypothesis that some sleep disorders, as PLM, may impair cognitive performance ${ }^{7}$.

All these sleep disorder presented among cases (CM II) and controls may affect sleep architecture, and consequently impair brain functions during infant critical developmental stages ${ }^{10}$. In the case of CM II patients, sleep disorders can provoke attention deficit, and further impair the cognitive functions already damaged by the $\mathrm{CM}$ II abnormalities ${ }^{1,11}$.

In conclusion, sleep disorders may impair cognitive functions, as attention, and contribute to poor quality of learning also in patients with CM II.

A significant difference was observed, between CM II 
patients and controls, in the frequency of RBD, PLMS and SAS events that are frequently responsible to the development of attention deficits. These findings emphasized the necessity of always evaluate the sleep of CM II patients, avoiding to exclusively crediting the presence of attention deficits and cognitive impairments to the central nervous system malformations.

\section{REFERENCES}

1. Gilbert JN, Jones KL, Rorke LB, Chernoff GF, James HE. Central nervous system anomalies associated with meningomyelocele, hydrocephalus, and the Arnold-Chiari malformation: reappraisal of theories regarding the pathogenesis of posterior neural tube closure defects. Neurosurgery 1986;18:559-564.

2. Koehler PJ. Historical vignette. Chiariís description of cerebelar ectopy (1891), with a summary of Clelandís and Arnoldís contributions and some early observations on neural-tube defects. J Neurosurg 1991; 75:823-826.

3. Vinck A, Maassen B, Mullaart R, Rotteveel J. Arnold-Chiari II malformation and cognitive functioning in spina bifida. J Neurol Neurosurg Psychiatry 2006;77:1083-1086.

4. Mirzai H, Erşahin Y, Mutluer S, Kayahan A. Outcome of patients with meningomyelocele: the Ege University experience. Childs Nerv Syst 1998;14:120-123.

5. Waters KA, Forbes P, Morielle A et al. Sleep-disordered breathing in children with myelomeningocele. J Pediatr 1998;132:672-681.

6. Nogués M, Cammarota A, Leiguarda R, Rivero A, Pardal A, Encabo H. Periodic limb movements in syringomyelia and syringobulbia. Mov Disord 2000;15:113-119.

7. Crabtree VM, Ivanenko A, OíBrien LM, Gozal D. Periodic limb movement disorder of sleep in children. J Sleep Res 2003;12:73-81.

8. Kaplan Y, Oksuz E. Association between restless legs syndrome and Chiari type 1 malformation. Clin Neurol Neurosurg 2008;110:408-410.

9. Lapierre O, Montplaisir J. Polysomnographic features of REM sleep behavior disorder: development of a scoring method. Neurology 1992;42:1371-1374

10. O'Brien LM, Mervis LMO, Holbrook CR et al. Neurobehavioral correlates of sleep-disordered breathing in children. J Sleep Res 2004;13:165-172.

11. Davidovitch M, Manning-Courtney P, Hartmann LA, Watson J, Lutkenhoff $\mathrm{M}$, Oppenheimer $\mathrm{S}$. The prevalence of attentional problems and the effect of methylphenidate in children with myelomeningocele. Pediatr Rehabil 1999:3:29-35.

12. Dise JE, Lohr ME. Examination of deficits in conceptual reasoning abilities associated with spina bifida. Am J Phys Med Rehabil 1998;77: 247-251.

13. Rechtschaffen A, Kales A. A manual of standardized terminology; techniques and scoring system for sleep stages of human subjects. Los Angeles: UCLA Brain Information Service / Brain Information Institute, 1968.

14. Consens FB, Chervin RD, Koeppe RA et al. Validation of a polisomnographic score for REM sleep behavior disorder. Sleep 2005;28:993-997.

15. Uliel S, Tauman R, Greenfeld M, Sivan Y. Normal polysomnography respiratory values in children and adolescents. Chest 2004;125:872-878.

16. Zucconi M, Ferri R, Allen R et al. The official World Association of Sleep Medicine (WASM) standards for recording and scoring periodic leg movements in sleep (PLMS) and wakefulness (PLMW) developed in collaboration with a task force from the International Restless Legs Syndrome Study Group (IRLSSG). Sleep Med 2006;7:175-183.

17. Brito GNO de. Escala de Avaliação do Comportamento Infantil para o Professor: EACI-P. 1. ed. Rio de Janeiro: Entreletras; 1999.

18. SPSS for Windows. Standard version. Release 10.0.1. SPSS Inc.1999.

19. Dauvilliers $Y$, Stal V, Abril B et al. Chiari malformation and sleep related breathing disorders. J Neurol Neurosurg Psychiatry 2007;78:1344-1348.

20. Banks S, Dinges DF. Behavioral and physiological consequences of sleep restriction. J Clin Sleep Med 2007;3:519-528.

21. Henriques Filho PS, Pratesi R. Abnormalities in auditory evoked potentials of 75 patients with Arnold-Chiari malformations type I and II. Arq Neuropsiquiatr 2006;64:619-623.

22. Henriques Filho PS, Pratesi R. Sleep apnea and REM behavior disorder in patients with Chiari malformations. Arq Neuropsiquiatr 2008;66: 344-349.

23. Berger AJ, Mitchell RA, Severinghaus JW. Regulation of respiration. N Engl J Med 1977;297:92-97.

24. Netick A, Orem J, Dement W. Neuronal activity specific to REM and its relationship to breathing. Brain Res 1977;120:197-207.

25. Hendricks JC, Morrison AR, Mann GL. Different behaviors during paradoxical sleep without atonia depend on pontine lesion site. Brain Res 1982;239:81-105.

26. Bass JL, Corwin M, Gozal D et al. The effect of chronic or intermittent hypoxia on cognition in childhood: a review of the evidence. Pediatrics 2004;114:805-816.

27. Bullock R, Todd NV, Easton J, Hadley D. Isolated central respiratory failure due to syringomyelia and Arnold-Chiari malformation. BMJ 1988;297:1448-1449.

28. Guyenet PG, Mulkey DK, Stornetta RL, Bayliss DA. Regulation of ventral surface chemoreceptors by the central respiratory pattern generator. J Neurosci 2005;25:8938-8947.

29. Bokinsky GE, Hudson LD, Weil JV. Impaired peripheral chemosensivity and acute respiratory failure in Arnold-Chiari malformation and syringomyelia. N Engl J Med 1973;288:947-948.

30. Rauzzino M, Oakes J. Chiari II malformation and syringomyelia. Neurosurg Clin N Am 1995;6:293-309. 